\title{
LETTER
}

Chronic Lymphocytic Leukemia

\section{COVID-19 vaccine efficacy in patients with chronic lymphocytic leukemia}

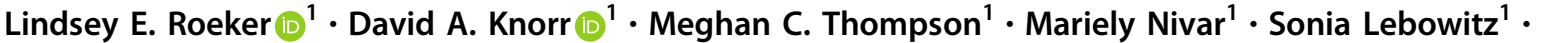 \\ Nicole Peters ${ }^{2}$ - Isaac Deonarine $\mathrm{Jr}^{1}$. Saddia Momotaj ${ }^{1}$ - Saumya Sharan ${ }^{3}$. Vanessa Chanlatte ${ }^{1}$. Bianca Hampton ${ }^{1}$. \\ Liana Butala ${ }^{2} \cdot$ Lindsay Amato $^{1} \cdot$ Angela Richford $^{3} \cdot$ Jessica Lunkenheimer $^{1} \cdot$ Kristen Battiato $^{1} \cdot$ Carissa Laudati $^{2}$. \\ Anthony R. Mato ${ }^{1}$
}

Received: 2 April 2021 / Revised: 21 April 2021 / Accepted: 27 April 2021 / Published online: 13 May 2021

(C) The Author(s), under exclusive licence to Springer Nature Limited 2021

\section{To the Editor:}

While randomized controlled trials demonstrated 94-95\% efficacy of severe acute respiratory syndrome coronavirus 2 (SARS-CoV-2) spike messenger RNA (mRNA) vaccines [1, 2], efficacy in immunocompromised patients has not been established. We aimed to understand serologic response to mRNA vaccination in patients with chronic lymphocytic leukemia (CLL), a population of interest given the immunocompromised state associated with this malignancy and disease-directed therapies, as well as incomplete immune responses following other vaccinations [3-10].

\section{Methods}

We examined 44 consecutive patients with CLL who received two doses of mRNA vaccine (BNT162b2 or mRNA-1273) between $1 / 2 / 21$ and $3 / 12 / 21$ and were tested for anti-SARS-CoV-2 S1/S2 antibodies. Serology testing was performed in routine clinical practice with the Liaison ${ }^{\circledR}$ SARS-CoV-2 S1/S2 IgG assay (DiaSorin; Saluggia, Italy) with $\geq 15 \mathrm{AU} / \mathrm{mL}$ constituting a positive result. Baseline demographics, treatment history and laboratory parameters prior to first dose of COVID-19 vaccine were collected. Logistic regression was used to examine relationship

Lindsey E. Roeker

roekerl@mskcc.org

1 Memorial Sloan Kettering Cancer Center, New York, NY, USA

2 Memorial Sloan Kettering Cancer Center, Basking Ridge, NJ, USA

3 Memorial Sloan Kettering Cancer Center, Commack, NY, USA between baseline characteristics and positive serology testing; all other statistics are descriptive. Analyses were performed using Stata 16 [11]. This retrospective study was institutional review board approved.

\section{Results}

Median age at time of vaccination was 71 years (range $37-89)$ and 23/44 (52\%) were male. Twenty-six patients $(59 \%)$ received at least one prior CLL-directed therapy. Eighteen (41\%) were actively treated at the time of vaccination (14 (32\%) with Bruton Tyrosine Kinase (BTK) inhibitor, 7 (16\%) with venetoclax, 14 (32\%) with antiCD20 monoclonal antibody (mAb) within 1 year). CLLdirected therapy was not held or modified at the time of vaccination. BNT162b2 was administered to 25/44 (57\%) and mRNA-1273 to $19 / 44(43 \%)$. Serology was tested a median of 21 days (range 14-48) following second vaccine dose. Twenty-three patients in this cohort of $44(52 \%)$ tested positive for anti-SARS-CoV-2 S1/S2 antibodies.

We found that treatment naïve patients (OR 56.7, 95\% CI 6.2-518) and those under age 70 years (OR 12.0, 95\% CI 2.9-50.5) were more likely to produce anti-SARS-CoV2 S1/S2 antibodies (Table 1). Production of antibodies was significantly less common in patients receiving BTK inhibitors at time of vaccination or in patients who received anti-CD20 mAb within 12 months. Anti-SARS-CoV-2 S1/ S2 antibodies were detected in 17/18 (94\%) of never treated patients vs. $6 / 26(23 \%)$ of treated patients. Additionally, $3 / 14(21 \%)$ of those receiving BTK inhibitors, 2/14 (14\%) of those who had received anti-CD20 mAb within 12 months, and $0 / 7(0 \%)$ of those receiving venetoclax with anti-CD20 mAb within 12 months tested positive for antiSARS-CoV-2 S1/S2 antibodies. 
Table 1 Baseline characteristics and association between baseline characteristics and positive anti-SARS-CoV-2 S1/S2 IgG result at least 14 days following 2nd dose of BNT162b2 or mRNA-1273 vaccine.

\begin{tabular}{|c|c|c|}
\hline Characteristic & \multicolumn{2}{|c|}{$\begin{array}{l}\text { Proportion, unless otherwise } \\
\text { specified }\end{array}$} \\
\hline \multicolumn{3}{|l|}{ Baseline characteristics } \\
\hline $\begin{array}{l}\text { Age at vaccination, median } \\
\text { (range) }\end{array}$ & \multicolumn{2}{|c|}{71 years $(37-89)$} \\
\hline Male & \multicolumn{2}{|l|}{$23 / 44(52 \%)$} \\
\hline \multicolumn{3}{|l|}{ CLL treatment history } \\
\hline Never treated & \multicolumn{2}{|l|}{$18 / 44(41 \%)$} \\
\hline Prior CLL-directed therapy & \multicolumn{2}{|c|}{$26 / 44(59 \%)$} \\
\hline Current CLL-directed therapy & \multicolumn{2}{|c|}{$18 / 44(41 \%)$} \\
\hline BTK inhibitor & \multicolumn{2}{|l|}{$14 / 44(32 \%)$} \\
\hline Venetoclax & \multicolumn{2}{|l|}{$7 / 44(16 \%)$} \\
\hline $\begin{array}{l}\text { Anti-CD20 monoclonal } \\
\text { antibody within } 1 \text { year }\end{array}$ & \multicolumn{2}{|c|}{$14 / 44(32 \%)$} \\
\hline \multicolumn{3}{|c|}{ Lab parameters prior to vaccination } \\
\hline IgG, median (range) & \multicolumn{2}{|c|}{776 mg/dL (294-1483) } \\
\hline ALC, median (range) & \multicolumn{2}{|c|}{5.6 cells $/ \mu \mathrm{L}(0.4-151.2)$} \\
\hline ANC, median (range) & \multicolumn{2}{|c|}{3.4 cells $/ \mu \mathrm{L}(0.9-8.3)$} \\
\hline \multicolumn{3}{|c|}{ Anti-SARS-CoV-2 S1/S2 antibody } \\
\hline Positive & \multicolumn{2}{|l|}{$23 / 44(52 \%)$} \\
\hline Negative & \multicolumn{2}{|c|}{$21 / 44(48 \%)$} \\
\hline $\begin{array}{l}\text { Predictors of positive antibody } \\
\text { response }\end{array}$ & Odds ratio & $\begin{array}{l}95 \% \text { confidence } \\
\text { interval, } p \text { value }\end{array}$ \\
\hline Age $<70$ vs. $\geq 70$ & 12.0 & $2.9-50.5, p=0.001$ \\
\hline $\begin{array}{l}\text { Never treated vs. prior-CLL } \\
\text { directed therapy }\end{array}$ & 56.7 & $6.2-518, p<0.001$ \\
\hline $\begin{array}{l}\text { Active observation vs. current } \\
\text { therapy }\end{array}$ & 16.7 & $3.6-77.7, p<0.001$ \\
\hline BTKi at time of vaccination & 0.14 & $0.031-0.60, p=0.009$ \\
\hline $\begin{array}{l}\text { Anti-CD20 monoclonal } \\
\text { antibody within } 1 \text { year }\end{array}$ & 0.071 & $0.013-0.39, p=0.002$ \\
\hline
\end{tabular}

\section{Discussion}

Given that immunocompromised patients were excluded from clinical trials testing SARS-CoV-2 spike mRNA vaccines $[1,2]$, understanding efficacy in this population is crucial. Patients with hematologic malignancy [12-20], particularly those with CLL [21-23], are of interest given prior reports suggesting poor outcomes following diagnosis of COVID-19. Furthermore, patients with CLL experience suboptimal vaccine efficacy, especially those receiving CLL-directed therapy [3-10]. For example, a recent report by Pleyer, et al. demonstrated a $4 \%$ response rate to the recombinant hepatitis $B$ vaccine in patients treated with BTK inhibitors versus a $28 \%$ response rate in treatmentnaïve patients. In that same report, $42 \%$ of BTK inhibitor treated patients and 59\% of treatment-naïve patients mounted a response to the recombinant herpes zoster vaccine. Collectively, these data suggest that BTK inhibitors profoundly impact response to vaccines for pathogens in which pre-existing immunity is not present.

In this study, we found that only half of vaccinated patients with CLL develop detectable anti-SARS-CoV-2 S1/S2 antibodies. Furthermore, we found a significant difference between rates of detectable anti-SARS-CoV-2 S1/S2 antibodies between treatment-naïve patients $(17 / 18,94 \%)$ and those who had received CLL directed therapy $(6 / 26,23 \%)$. These striking findings suggest that vaccination in patients with CLL may not confer the efficacy that we expect in the general population, particularly in patients receiving CLLdirected therapy. These findings have further implications for a broader population as BTK inhibitors, venetoclax, and anti$\mathrm{CD} 20 \mathrm{mAb}$ are commonly used for other diseases. These data support conducting prospective clinical studies of vaccine efficacy in patients with CLL and other immunocompromising conditions. While we await establishment of herd immunity, specific guidance for patients with CLL are warranted as the current Center for Disease Control and Prevention recommendations regarding relaxed personal protective equipment use when around other vaccinated people may not apply to this population [24]. Without consistent antibody responses, patients with CLL should continue to exercise extreme caution following vaccination until further data on clinical efficacy are available.

Acknowledgements This research was supported in part by the NIH/NCI Cancer Center Support Grant P30 CA008748, NCI 1K08CA248966-01 (DAK), and research support from Pfizer (DAK and ARM).

\section{Compliance with ethical standards}

Conflict of interest LER has served as a consultant for AbbVie, AstraZeneca, Pharmacyclics, Vaniam group, and Verastem, holds minority ownership interest in Abbott Laboratories, and has received research funding (paid to the institution) from Pfizer and Aptose Biosciences outside of the submitted work. DAK receives research support on COVID-19 from Pfizer. MCT has received honoraria from MJH Life Sciences, VJ Heme Onc, Curio Science. KB has consulted for AbbVie and Janssen. ARM has served as a consultant and received research funding from Curio Science, TG Therapeutics, Celgene, Janssen; AbbVie, Adaptive, Loxo, Nurix, Genmab, Genentech, Pfizer, Octopharma, Pharmacyclics, AstraZeneca, Sunesis, DTRM, Gilead, and Johnson \& Johnson. He served as DSMB member at TG Therapeutics. All other authors declare no competing interest.

Publisher's note Springer Nature remains neutral with regard to jurisdictional claims in published maps and institutional affiliations.

\section{References}

1. Polack FP, Thomas SJ, Kitchin N, Absalon J, Gurtman A, Lockhart S, et al. Safety and efficacy of the BNT162b2 mRNA Covid-19 vaccine. N Engl J Med. 2020;383:2603-15. 
2. Baden LR, El Sahly HM, Essink B, Kotloff K, Frey S, Novak R, et al. Efficacy and safety of the mRNA-1273 SARS-CoV-2 vaccine. N Engl J Med. 2021;384:403-16.

3. Pleyer C, Ali MA, Cohen JI, Tian X, Soto S, Ahn IE, et al. Effect of Bruton tyrosine kinase inhibitor on efficacy of adjuvanted recombinant hepatitis B and zoster vaccines. Blood. 2021;137:185-9.

4. Mauro FR, Giannarelli D, Galluzzo CM, Vitale C, Visentin A, Riemma C, et al. Response to the conjugate pneumococcal vaccine (PCV13) in patients with chronic lymphocytic leukemia (CLL). Leukemia. 2021;35:737-46.

5. Sun C, Gao J, Couzens L, Tian X, Farooqui MZ, Eichelberger $\mathrm{MC}$, et al. Seasonal influenza vaccination in patients with chronic lymphocytic leukemia treated with Ibrutinib. JAMA Oncol. 2016; 2:1656-7.

6. Douglas AP, Trubiano JA, Barr I, Leung V, Slavin MA, Tam CS. Ibrutinib may impair serological responses to influenza vaccination. Haematologica. 2017;102:e397-e9.

7. Zent CS, Brady MT, Delage C, Strawderman M, Laniewski N, Contant PN, et al. Short term results of vaccination with adjuvanted recombinant varicella zoster glycoprotein E during initial BTK inhibitor therapy for CLL or lymphoplasmacytic lymphoma. Leukemia. 2020:1-4. [E-pub ahead of print].

8. Parrino J, McNeil SA, Lawrence SJ, Kimby E, Pagnoni MF, Stek JE, et al. Safety and immunogenicity of inactivated varicella-zoster virus vaccine in adults with hematologic malignancies receiving treatment with anti-CD20 monoclonal antibodies. Vaccine. 2017;35:1764-9.

9. Sinisalo M, Aittoniemi J, Oivanen P, Kayhty H, Olander RM, Vilpo $\mathrm{J}$. Response to vaccination against different types of antigens in patients with chronic lymphocytic leukaemia. Br J Haematol. 2001; 114:107-10.

10. Hartkamp A, Mulder AH, Rijkers GT, van Velzen-Blad H, Biesma DH. Antibody responses to pneumococcal and haemophilus vaccinations in patients with B-cell chronic lymphocytic leukaemia. Vaccine. 2001;19:1671-7.

11. StataCorp. Stata Statistical Software: Release 16. College Station, TX: StataCorp LLC; 2019.

12. Li Q, Chen L, Li Q, He W, Yu J, Chen L, et al. Cancer increases risk of in-hospital death from COVID-19 in persons $<65$ years and those not in complete remission. Leukemia. 2020;34:2384-91.

13. He W, Chen L, Chen L, Yuan G, Fang Y, Chen W, et al. COVID-19 in persons with haematological cancers. Leukemia. 2020;34:1637-45.
14. Passamonti F, Cattaneo C, Arcaini L, Bruna R, Cavo M, Merli F, et al. Clinical characteristics and risk factors associated with COVID-19 severity in patients with haematological malignancies in Italy: a retrospective, multicentre, cohort study. Lancet Haematol. 2020;7:e737-e45.

15. Breccia M, Piciocchi A, De Stefano V, Finazzi G, Iurlo A, Fazi P, et al. COVID-19 in Philadelphia-negative myeloproliferative disorders: a GIMEMA survey. Leukemia. 2020;34:2813-4.

16. Varma A, Kosuri S, Ustun C, Ibrahim U, Moreira J, Bishop MR, et al. COVID-19 infection in hematopoietic cell transplantation: age, time from transplant and steroids matter. Leukemia. 2020;34: 2809-12.

17. Barbui T, Vannucchi AM, Alvarez-Larran A, Iurlo A, Masciulli A, Carobbio A, et al. High mortality rate in COVID-19 patients with myeloproliferative neoplasms after abrupt withdrawal of ruxolitinib. Leukemia. 2021;35:485-93.

18. Cattaneo C, Pagani C, Cancelli V, Imberti L, Roccaro AM, Notarangelo LD, et al. Reduction in the rate and improvement in the prognosis of COVID-19 in haematological patients over time. Leukemia. 2021;35:632-4.

19. van Doesum J, Chinea A, Pagliaro M, Pasquini MC, van Meerten T, Bakker M, et al. Clinical characteristics and outcome of SARS-CoV2-infected patients with haematological diseases: a retrospective case study in four hospitals in Italy, Spain and the Netherlands. Leukemia. 2020;34:2536-8.

20. Dhakal B, D'Souza A, Chhabra S, Hari P. Multiple myeloma and COVID-19. Leukemia. 2020;34:1961-3.

21. Mato AR, Roeker LE, Lamanna N, Allan JN, Leslie L, Pagel JM, et al. Outcomes of COVID-19 in patients with CLL: a multicenter international experience. Blood. 2020;136:1134-43.

22. Scarfo L, Chatzikonstantinou T, Rigolin GM, Quaresmini G, Motta M, Vitale C, et al. COVID-19 severity and mortality in patients with chronic lymphocytic leukemia: a joint study by ERIC, the European Research Initiative on CLL, and CLL Campus. Leukemia. 2020;34:2354-63.

23. Fürstenau M, Langerbeins P, De Silva N, Fink AM, Robrecht S, von Tresckow J, et al. COVID-19 among fit patients with CLL treated with venetoclax-based combinations. Leukemia. 2020;34:2225-9.

24. Center_for_Disease_Control_and_Prevention. When You've Been Fully Vaccinated: How to Protect Yourself and Others https://www. cdc.gov/coronavirus/2019-ncov/vaccines/fully-vaccinated.html2021 